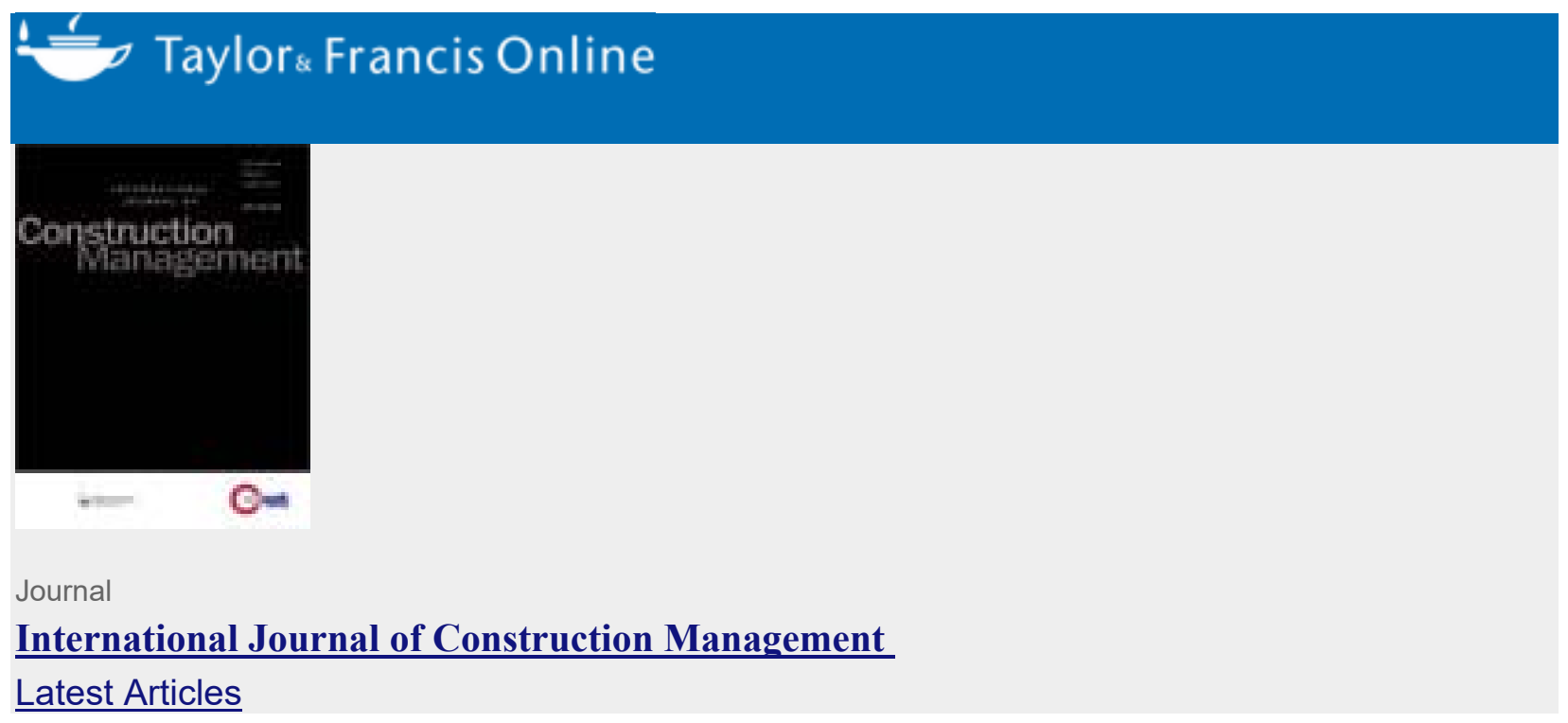

\title{
Gauging parameters for e-procurement acquisition in construction businesses in Nigeria
}

Adedeji Afolabi,Eziyi Ibem, Egidario Aduwo, Patience Tunji-Olayeni, Olufunke Oluwunmi \&Emmanuel Ayo-Vaughan

Published online: 14 Jun 2019

- $\quad$ https://doi.org/10.1080/15623599.2019.1627504
Abstract
e-Procurement tools build on traditional methods of procurement by integrating the processes and people involved in construction businesses through Internet-supported information and communication technologies. In spite of how crucial these tools are there is a need to for strategic management decision making before they are procured and used because of the cost and technical implications involved. The study examined the gauging parameters for e-procurement acquisition in the construction businesses by firms and organisations in Nigeria. The study utilized a survey approach of actual users of e-procurement tools and technologies in the Nigerian construction industry. A total of 759 actual users were identified from several cities in the study area. Data obtained were analyzed in stacked bars, frequencies and categorical regression. The study presented the significant gauging parameters that can influence e-procurement technology acquisition. They include staff strength of the construction business, presence of quality internet facilities, security level and validation capacity of e- 
procurement transactions, supportive policy and legislative framework in e-procurement usage and computer literacy level of construction stakeholders participating in an eprocurement environment. In conclusion, the study developed a framework to guide construction businesses in e-procurement technology acquisition. Every construction organization should have unique metrics for measuring and predicting technology acquisition in order to avoid obsolescence and waste of scarce resources. There is a need for supportive policies and legislative frameworks that encourage e-procurement usage among construction stakeholders in the different countries.

Keywords: Acquisition, construction businesses, construction industry, e-procurement, parameters

\section{Additional information}

\section{Funding}

The research was made possible through funding provided by Covenant University Centre for Research, Innovation and Discovery (CUCRID), Covenant University through the grant no. CUCRID RG14.12.14/FS. 